\title{
Paisaje urbano y rural de la ciudad de Andújar: el caso de las torres mirador
}

\author{
Jesús Ángel Palomino León *
}

De la Edad Media el paisaje de Andújar hereda un magnífico recinto amurallado, un gran puente sobre el Guadalquivir y cinco parroquias que se están construyendo a finales del s. XV. Durante la Edad Moderna, principalmente s. XVII y s. XVIII, la actividad del cabildo municipal será: las obras del puente, que siempre estuvo amenazado por las riadas; las obras de las Casas de Comedias (actual Ayuntamiento) que le ocurría igual que al puente, siempre en obras; la lucha contra las mortíferas oleadas de peste; mantener el abastecimiento de trigo; el continuo paso de tropas y levas de hombres; y los infinitos pleitos sobre privilegios y jurisdicción que Andújar quería conservar y fue un pozo sin fondo para los recursos económicos.

El paisaje urbano fue cambiando hasta resultar la ciudad que hemos conocido. La actividad constructiva fue importante: numerosos conventos, casas solariegas -cada linaje tenía la suya y fueron numerosos-, posadas, molinos de aceite y aceñas, y las continuas obras de remodelación y mantenimiento que originaban. Calles estrechas pero con numerosos altozanos que se abren ante palacios o conventos y que se coronan con miradores. Las calles estuvieron empedradas en su mayoría con gruesos cantos de río. La arquitectura oficial también ba-sada en fachadas porticadas. Esto conformó espacios urbanos recreados en una estética italianizante. La plaza de Santa María fue exclusiva del poder público y eclesiástico: el cabildo de estilo gótico isabelino, las escribanías y pósito, las pescaderías, la torre de la ciudad (Torre del Reloj) y la cárcel real contigua a ella, y la iglesia de Santa María la Mayor. En la plaza del Mercado en cambio hizo aparición el poder nobiliario: junto a la iglesia de San Miguel y la Casa de Comedias hubo tres magníficos palacios. Esta plaza era una lección de Historia del Arte; si diéramos un corte estratigráfico a la cronología de sus elementos tendríamos que comienza con las dos portadas laterales de la parroquia fechadas en I48396 por el escudo del prelado Luis Osorio; continúa con la portada renacentista de los pies que lleva el escudo del cardenal Merino (I 523 35); a la torre le queda un pequeño resto del escudo del obispo Delgado ( I566-77); el artesonado del bajo coro lo lleva del obispo Sarmiento (I 580- I 595); la portada del palacio de los Piédrola llevaba la fecha de 1577 (conocido como "de la condesa de Gracia Real"); el de los Pérez Serrano ("del marqués del Puente") fue construido en los años cercanos a 1619, por la heráldica del matrimonio que lo habitó; la casa de Comedias se acaba en I63I como reza la lápida de su fachada; la fuente acabada en 1733; el palacio del marqués de San Rafael posterior a 1758; la nueva fachada neoclásica del ayuntamiento de 179|. Girando sobre un mismo eje se hacía un recorrido desde el arte gótico hasta el neoclásico, como en la rotonda de un museo.

* Licenciado en Humanidades. 
Dentro del capítulo de las parroquias, la más interesante es la de Santa María la Mayor; pocas como ésta tendrán dos cabeceras y dos torres. Primero tuvo una cabecera gótica y en los primeros años del s. XVII se construyó una nueva de estilo manierista en los pies del templo y en la cabecera primitiva se abrió una portada. En una de sus esquinas queda lo que fue una torre fechada por una lápida gótica en I 467 y en la otra esquina una torre de ladrillo de la primera mitad del s. XVII.

Para acabar de dibujar este paisaje veamos como sobre el recinto amurallado se creó un nuevo cinturón de fundaciones religiosas y dos grandes arrabales. De levante a poniente teníamos el convento de Capuchinos; de San Eufrasio de la orden de Trinitarios, de la Limpia Concepción de Trinitarias, de San Juan de Dios, de Franciscanos, de Capuchinas, de monjas Mínimas y el de la Victoria de frailes Mínimos.

La disposición de los arrabales principales estuvo determinada por su posición frente a las murallas: el de San Bartolomé se organizó en forma radial a partir de la plaza Vieja, donde estaba el castillo, de aquí partían seis calles -Tiradores, San Bartolomé, Vendederas, Calancha, La Plaza y San Francisco-.

El de San Miguel, en cambio, se constituía por un eje principal que arrancaba de la puerta conocida como de la Virgen María -por tener una capilla de la Virgen de Consolación-y que es la corredera de Capuchinos donde se abren calles perpendiculares y que se continúa intramuros con la calle Maestra.

En el complejo funcionamiento del entramado urbano de una ciudad de origen musulmán, como es el caso de Andújar, donde ningún emplazamiento de edificio es inocente, hay que tratar el tema de la elevación de elementos arquitectónicos como son las espadañas, las torres campanarios, los miradores, las capillas mayores en forma de torre.
Se llega a crear un diálogo entre los distintos poderes a través de las construcciones en altura. La Iglesia, el Cabildo Municipal o la nobleza compiten por copar el espacio visible desde extramuros como garantía de su poder. Las parroquias levantan sus torres, los conventos alzan sus espadañas y capillas mayores, el poder local levanta su torre civil o recalza las murallas y las cubre de sillería, la nobleza añade en sus casas principales las torres mirador como cierta expresión de refinamiento en su vida privada y como demostración de riqueza económica y prestigio en competencia con otros linajes.

La cercanía entre estas construcciones no era siempre de buena vecindad. Un ejemplo lo tenemos entre la torre de la ciudad y la torre de la parroquia de Santa María la Mayor, con muy pocos metros de separación entre ellas. El cabildo municipal hizo demoler la torre parroquial hasta la altura de la cornisa, de lo que se siguió un pleito en la Real Chancillería de Granada !

El alzado de las casas de Andújar era normalmente de planta baja y alta, que junto a la suave ascensión de las terrazas del río producía una fácil prelación entre los edificios. Pocas moles se destacaban si no eran los tejados de las parroquias o la Casa de Comedias que tenía tres ordenes de miradores. Los jesuitas cuando construyen su colegio le dan demasiada altura para el caserío y se producen problemas. Así don Manuel de Escabias se dirige al Cabildo oponiéndose a la pretensión que tiene la Compañía de Jesús de elevar los edificios en construcción en la calle de Santo Domingo a una altura que causaría grandes perjuicios a él y a los demás vecinos del barrio por impedir las vistas al campo desde las azoteas y miradores?

Las torres y miradores fueron abundantes en casas solariegas y también en conventos. El material constructivo fue el ladrillo y el tapial. El último cuerpo era el que se porticaba gene-

I CUBERO DOMÍNGUEZ, J:: Monumentalidad religiosa de Andújar en la Modernidad, pág. 31.

2 A.H.M.A. Leg. 29. AA.CC. Cabildo del 9-II- 1637. 
ralmente con dos arcos en cada lado y con una moldura que separaba este cuerpo del resto de la torre.

Otra característica es que son elementos que pueden ser añadidos en un momento posterior a la construcción del edificio o eliminados en un momento anterior a la destrucción del propio edificio. De todo esto veremos ejemplos.

\section{Torres}

La que ha perdurado hasta hoy como ejemplo clásico de estas construcciones es la conocida como Casa de la Torre, en la calle Maestra, que dominaba la parte de la vega del río y la entrada de la ciudad por el camino real de Madrid. Su planta es un polígono irregular de cinco lados que se adapta a la esquina donde forma chaflán. De estilo renacentista pertenecía al mayorazgo que fundó don Cristóbal de Cárdenas Valdivia. Su silueta ha marcado las vistas de Andújar desde el s. XVI.

Otra torre similar se hallaba en la casa de los Messía en el altozano de Santa Marina, compitiendo con la espadaña de la iglesia, a muy poca distancia de ella. La casa era del mayorazgo fundado por doña Catalina María Luce$\mathrm{na}^{3}$. Se puede apreciar en fotografías antiguas. Formaba la esquina con la accesoria de Santa Marina, hoy calle Mezquita; no debió de formar chaflán con la esquina como se puede apreciar en un plano del primer tercio del s. XX. La torre desapareció antes que la casa, que lo hizo en los años setenta.

Otro ejemplo de importancia fue la torre de la casa de los Piédrola, comúnmente conocida como casa de la condesa de Gracia Real, en la plaza del Mercado y haciendo esquina con la calle del Toril, desaparecida en los años cuarenta de este siglo ${ }^{4}$. De planta cuadrada y en uno de los ángulos de esta gran plaza, donde competía con la gran torre parroquial de San Miguel, las Casas de Comedias porticadas en toda la longitud de su fachada y otras casas con miradores.

Un cuarto ejemplo existía en el convento de Jesús María de MM. Mínimas, se encontraba sobre la capilla mayor del templo que se cubre con un artesonado y que servía de piso a la torre mirador, fue desmontada en los años cuarenta de este siglo, seguramente para usar sus materiales. La planta era cuadrada y en vez de columna en cada lateral tenía un pilar. El resto del edificio sí ha llegado hasta nosotros con ciertas amputaciones.

Gracias al Catastro del marqués de Ensenada podemos encontrar otra de estas torres en la calle Cepeda, propiedad de don Juan de Cárdenas Ponce, con 33 varas de frente por 49 de fondo. Se describe la casa con seis cuartos bajos de habitación, cocina, dos patios con un pozo cada uno, dos caballerizas, una con un corral con pozo, dos corrales grandes, un sótano, una bodega para aceite de 3.000 arrobas. El segundo cuerpo con cinco cuartos de habitación, tres graneros, dos pajares y una cámara. En el tercer y último cuerpo, una torre ${ }^{5}$.

Es necesario añadir las torres que no se cubrían con arquerías sino con una terraza, como es el caso de la conocida como casa de los Niños de Don Gome, en la calle Maestra. Casa solar de los Valdivia, de origen granadino y que construyó la fachada de su casa como una torre cuadrada con la portada de blasones añadida a una de sus caras. Este edificio quedaba así integrado en el ángulo que formaba la muralla entre las torres de la Silera que se hallan a su espalda, la torre ochavada que hubo justo en el ángulo de la muralla y las que defendían la Puerta de la Virgen que quedaba alineada con el lateral de la casa solariega.

Un caso aún más avanzado fue el de la casa de los Quero en la Puerta del Alcázar, donde

3 Archivo Histórico Provincial de Jaén. Leg. 7596, fol. 366. Catastro de Ensenada. 1752.

4 Desapareció toda la manzana y la calle del Toril.

5 A.H.P.J. Leg. 7596, fol. 370. Catastro de Ensenada. 1752. 
se usó una torre de la muralla como terraza mirador. En I80 I se autoriza a don Gome de Quero para enlazar su casa con la muralla mediante un arco por encima de la callejuela que sale a la Puerta del Alcázar para que le sirva como terrado, con la condición de encargarse de las reparaciones de la muralla ${ }^{6}$. Hoy se conserva la torre con esta misma función integrada en la casa y con el arco que sobre la calle se realizó.

\section{GALERÍAS}

Los miradores o galerías, a diferencia de las torres que abrían todos sus lados, estaban orientados en la dirección de la fachada sobre la cual se asentaban y abrían más arcos que las torres de planta cuadrada, desde tres arcos hasta seis. Fueron muy abundantes.

El primero que veremos es el de la casa del conde de la Quintería, actual Palacio de Justicia, fechado en 1700 en las enjutas de los arcos, muy posterior al resto de la casa que data de la segunda mitad del s. XVI. Se alza como una torre en medio de la línea de fachada de la casa, sus arcos de medio punto fabricados en cantería son de una tradición clásica. Tiene la altura justa para alcanzar a ser visto desde fuera de la muralla de la Puerta del Alcázar; domina no sólo el altozano donde se encuentra sino toda la zona de la vega hacia el Sur.

Detrás de éste, en la calle de los Viejos, hubo otro en el hospital de los Honrados Viejos, fechado en 1609. Con la misma orientación y de tres vanos adintelados como se aprecia en un dibujo del pintor Cerezo que lo dibujó y que es el único documento que lo recuerda.

Similar al primero pero dentro del casco urbano es el mirador de una casa Valenzuela desaparecida, que estuvo situada en la calle
Juan Robledo, en un ángulo que mira al Sur y que domina un gran trozo de la calle. Son tres arcos rebajados que coronaban la portada de ingreso.

Un mirador muy parecido y de una casa del mismo linaje Valenzuela existió en la calle Fernando Quero, ocupando un lado del ángulo que formaba la casa en el altozano con orientación hacia el Oeste, sobre la portada. Controlaba el altozano y competía con el convento de Santa Clara y con la parroquia de Santiago que estaban situados a pocos metros.

Otra galería desaparecida es la que coronó la fachada de la casa de los Pérez Serrano, conocida como del Marqués del Puente de la Virgen, en la plaza del Mercado. Seis arcos de medio punto con bolas de vidrio en las enjutas y que cumplía una auténtica función de mirador pues esta plaza era el entorno urbano donde se ofrecían obras de teatro y fiestas de toros.

En el capítulo de construcciones conventuales tenemos otro ejemplo en la iglesia de las monjas trinitarias de la Limpia Concepción donde una estructura de tres vanos rectangulares corona la fachada; esto le da mayor importancia visual, dominando un amplio radio con orientación Sur.

Pasando al Catastro de Ensenada encontramos numerosas casas que tuvieron galerías y miradores:

- unas, propiedad del conde de la Quintería y muy cercanas a la anteriormente estudiada en la Puerta del Alcázar ${ }^{7}$.

- la plaza del Mercado fue un conjunto de miradores; a los ya vistos hay que añadir los siguientes: una casa propiedad del conde de la Quintería ${ }^{8}$, otra de don Miguel Caro

6 A.H.M.A. Leg. 80. AA.CC. Cabildo del 17-II-1801.

7 A.H.P.J. Leg. 7596, fol. 66. Catastro de Ensenada. 1752. ... otras casas en la misma calle Puerta del Alcázar, de 23 varas de frente por 20 de fondo. En bajo, una cocina, una caballeriza, con su pajar, un patio con su pozo, un sótano y un corral. En alto, cuatro habitaciones, una cocina, un corredor, un granero y una galería.

8 A.H.P.J. Leg. 7596, fol. 67. Catastro de Ensenada. 1752. ... casa en la plaza del Mercado, de 6 varas de frente por 15 de fondo. En bajo, tres cuartos, una cocina, un sótano, un patio con pozo, un corral. En alto, tres cuartos y una galería. Linda por arriba con cocheras de don Miguel Jurado. Linda por abajo con casa de don Juan de Vargas. 
Dávila ${ }^{9}$, otra de don García Sirvente Pérez de Vargas ${ }^{10}$, y otra de don Juan Pérez de Vargas Albarracín Piédrola y Benavides "I.

- la calle Maestra también contó con más exponentes de este tipo como una del conde de la Quintería ${ }^{12}$.

\section{TORRES Y MIRADORES EN LAS HACIENDAS RURALES}

Si extendemos el ámbito de nuestro estudio al medio rural comprobamos que se dan las mismas características en las haciendas o casas cortijos que en las casas urbanas. Las torres mirador funcionaron como observatorios del paisaje pero también como torres vigías y como denominador del poder del propietario. Un rasgo singular de estas torres es que se ven desde el camino real o arrecife que discurría por lo que ahora es la vía de comunicación de la autovía de Madrid a Sevilla, no sólo en el caso de las que están situadas en la falda de Sierra Morena y que por su altura lo domina, sino en las que estando situadas en la otra orilla del río Guadalquivir toman la altura necesaria para ver y hacerse ver desde el dicho camino. Veamos a continuación una serie de ejemplos.

El cortijo de la Aldehuela situado cerca de la carretera de los Rubiales ${ }^{13}$, ocupa el emplazamiento de una antigua fortaleza medieval. Su construcción actual se fecha en 1660, forman- do un conjunto de ermita, casa, bodega y casa de servicio.

En el Catastro de Ensenada pertenecen a don García Sirvente Pérez de Vargas que lo refleja de la siguiente forma ${ }^{14}$ : una casería en el sitio y pago de la Aldehuela, que dista de Andújar tres cuartos de legua. Con dimensiones de 64 varas de frente por 60 de fondo. Con ermita, sacristía y campana. Tres patios, dos pozos, cuatro corrales, 14 habitaciones de aceituneros, una cochera, dos caballerizas, dos despensas, dos cuartos, un amasadero, un horno de pan cocer, una cocina, un tinado. En alto tiene seis cuartos, dos pajares, una torre, una sala cocina, harineros y cebadero. Dentro de la casería hay un molino para sacar aceite de tres vigas y piedra, parada de tinajones, patio; la bodega tenía capacidad de 1.300 arrobas.

La pieza de tierra donde se encuentra la casa cortijo era de secano con 97 fanegas, 30 con | 6 | olivas y 37 de monte alto y bajo, con 500 encinas y 6 pinos. Linda a levante con estacares de doña Ana Valenzuela Medinilla. A poniente con chaparral de don Antonio Valenzuela Quero. Al Norte con olivas del Colegio de la Compañía. Al Sur con el chaparral anterior.

La conocida como Casa de la Torre en el camino de la Ropera ${ }^{15}$, es una construcción de una sola crujía con la torre en un extremo y perteneciente al s. XVII por la rejería que se conservaba en los vanos.

9 A.H.P.J. Leg. 7596, fol. 550. Catastro de Ensenada. 1752. Una casa principal en el Mercado, de su morada, de 30 varas de frente por 20 de fondo. En bajo tiene patio y claustro. En el tercer piso un mirador. Linda por arriba con casa del conde de la Quintería. Linda por abajo con casas propias.

I0 A.H.P.J. Leg. 7596, fol. I56v. Catastro de Ensenada. 1752. Unas casas en la plaza del Mercado, del vínculo que fundó Manuel Salcedo, de 1 I varas de frente por 18 de fondo. Zaguán, patio, pozo, corredores, sala, un cuarto, despensa, sótano, caballeriza, corral; en alto, cocina, mirador y dos cámaras. Linda por arriba con otras casas accesorias de don Miguel Caro Dávila. Linda por abajo con corrales de don Juan Pérez de Vargas Castrillo.

II A.H.P.J. Leg. 7596, fol. 243. Catastro de Ensenada. 27-IX-I752. Unas casas en la plaza del Mercado, de 6 varas de frente por II de fondo. Dos cuartos, entresuelo, cocina, tres órdenes de miradores. Linda por arriba con casa de don Miguel Jurado. Linda por abajo con casa del conde de la Quintería.

12 A.H.P.J. Leg. 7596, fol. 68v. Catastro de Ensenada. 1752. Una casa en la calle Maestra, de 40 varas de frente y 44 de fondo. En bajo, ocho cuartos, un sótano, un patio con pozo, un huerto, una cocina, dos caballerizas y corral. En alto, seis cuartos, una cocina, dos graneros, un corredor y una galería. Linda por arriba con casa de don Alonso de Valenzuela. Linda por abajo con casas propias.

Esta casa seguramente es la que se observa en una fotografía de la Casa de la Torre de principios de siglo.

13 Coordenadas U.T.M. 30SVHI34I32.

14 Archivo Histórico Provincial de Jaén. Leg. 7596, fol. 165.

15 Coordenadas U.T.M. 30SVHO6।I21. 
La torre de la casería llamada del Palomar, a la altura del kilómetro 314 de la autovía de Andalucía, en cierto estado de abandono y que presenta la misma estructura de todas las torres vistas excepto que no lleva arcos sino vanos adintelados ${ }^{16}$.

Cerca del poblado de San José de Escobar, otra torre con los arcos rebajados y dominando la vega del río Guadalquivir y el camino real ${ }^{17}$.

En la carretera de la Parrilla, en los últimos kilómetros antes de conectar con la de Puertollano estaba la casa del Horcajuelo con una gran torre centralizada en su fachada donde estaba el vano de entrada, un escudo, hornacina y espadaña.

Casa con mirador tenemos en la finca de la Quintería, a diez kilómetros de Andújar en la carretera de Los Villares ${ }^{18}$. Se alza sobre la parte central del tejado porticándose en los cuatro lados. En cierta medida recuerda al mirador de la casa de la Quintería en la Puerta del Alcázar, ya visto.

\section{FACHADAS PORTICADAS}

Otro capítulo de la estética de las arquerías que nos ayudará a cerrar este panorama del paisaje constructivo y los ámbitos porticados son los portales o fachadas porticadas. Éstas son exclusivas del poder civil. Prácticamente todos los edificios del poder local estuvieron porticados pero con una función distinta a las casas de las familias del estamento noble, en estas las dos primeras plantas quedaban cerradas al exterior como una casa fuerte, con puertas de clavos y rejas forjadas. Los edificios del cabildo municipal cumplían una función económica pues en los portales de la Alhóndiga, de las Pescaderías o del Rastro se producía la parte de la actividad comercial de la época, mientras que los miradores de la Casa de Comedias proporcionaban ingresos como palcos en los acontecimientos festivos de la ciudad.

Con este trabajo hemos intentado acercar nuestro conocimiento a lo que fue el alzado de una ciudad media del valle del Guadalquivir desde el final del s. XV hasta nuestros días. Lo que sobresalía de la altura media de los tejados, su funcionalidad que sin duda era la de observatorio del paisaje, de solarium, como elemento de poder urbano.

\footnotetext{
16 Coordenadas U.T.M. 30SVHI63I2I.

17 Coordenadas U.T.M. 30SVHI6I088.

18 Coordenadas U.T.M. 30SVHI66082.
} 


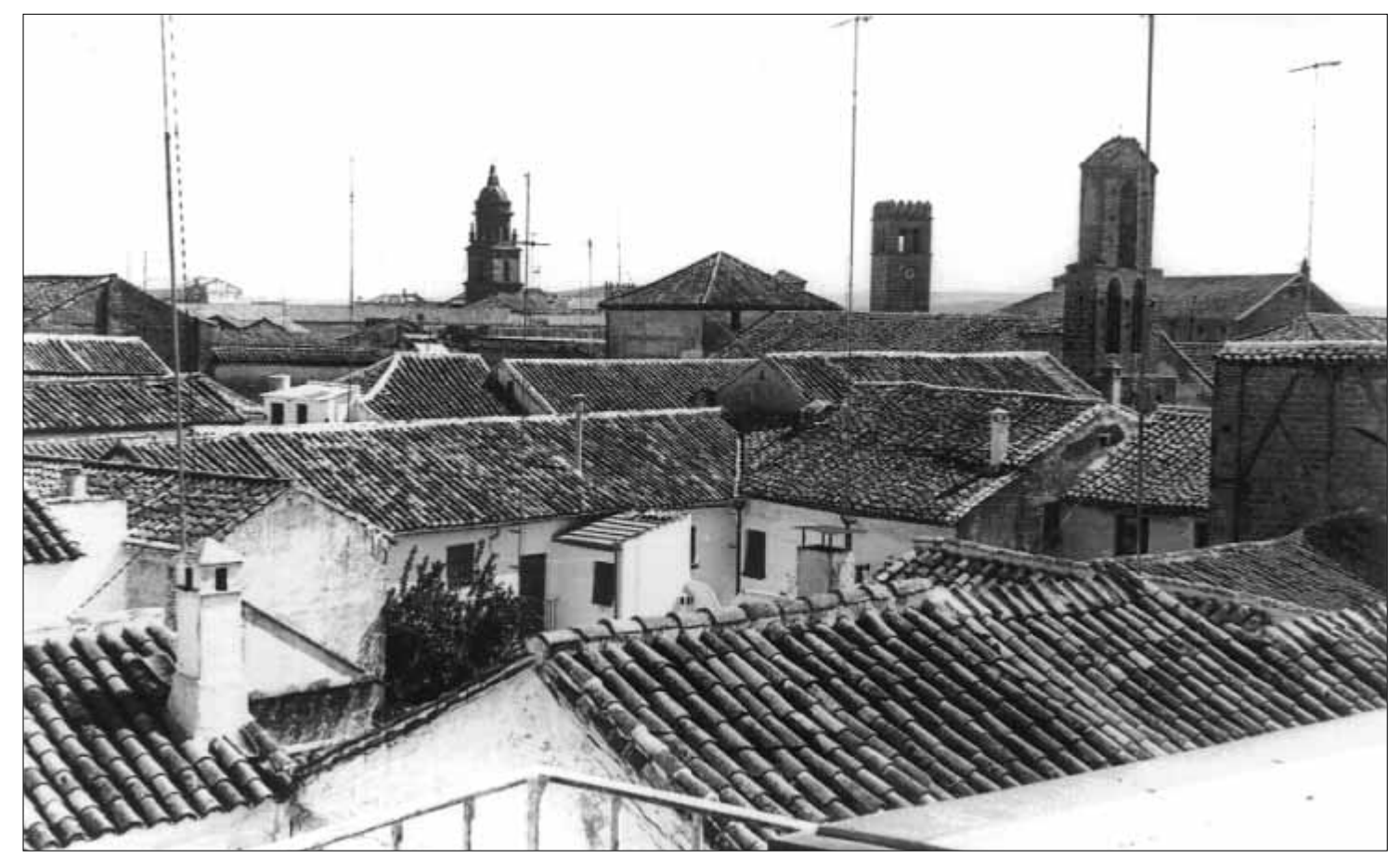

Fig. I. Vista desde el altozano de Sto. Domingo hacia el Nordeste.

Espadaña de Sta. Marina, Torre del Reloj y Torre de San Miguel.

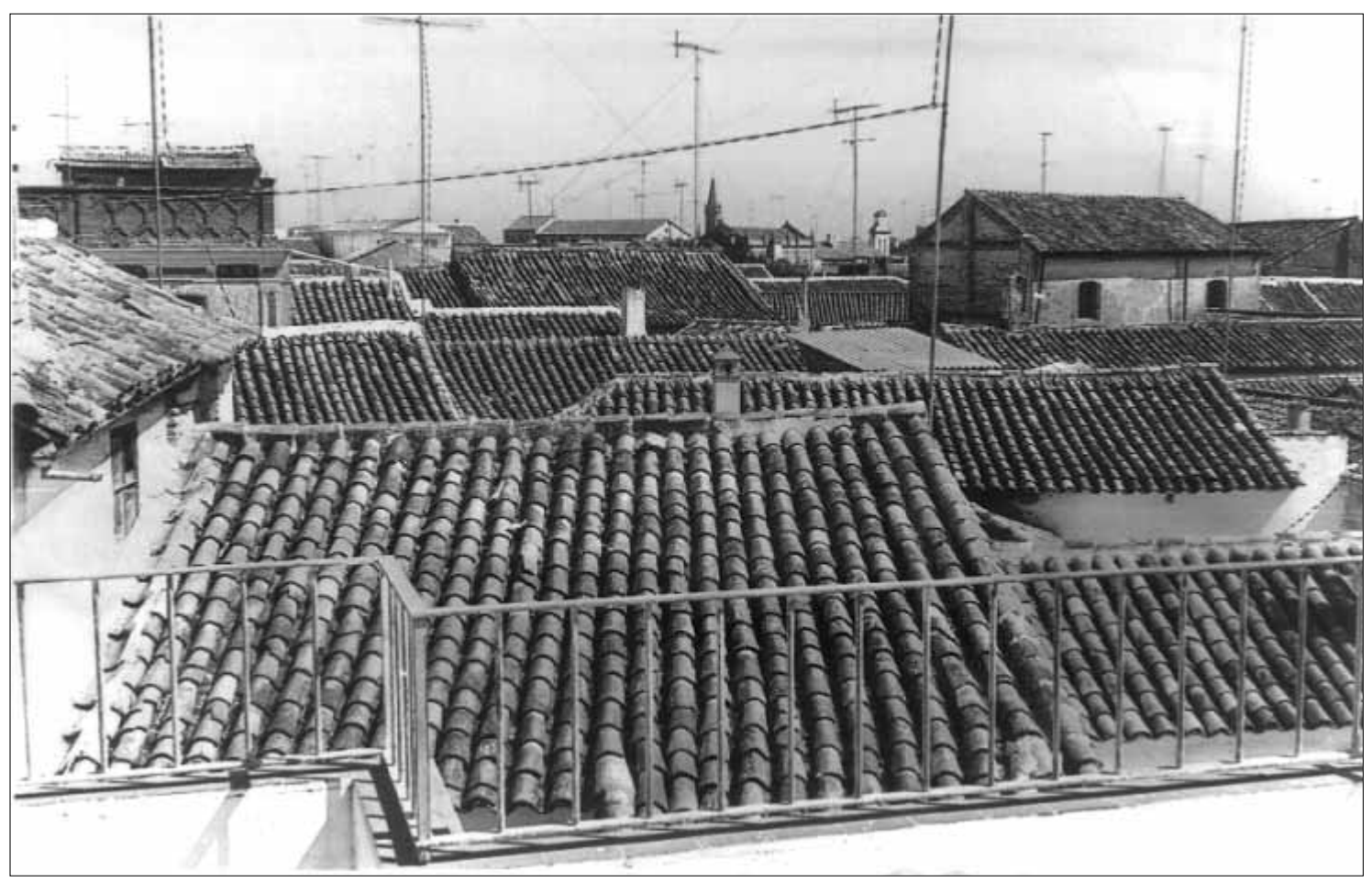

Fig. 2. Vista desde el altozano de Sto. Domingo hacia el Noroeste. Al fondo, torre neogótica y espadaña de San Juan de Dios. Este paisaje de tejados ha desaparecido totalmente. 


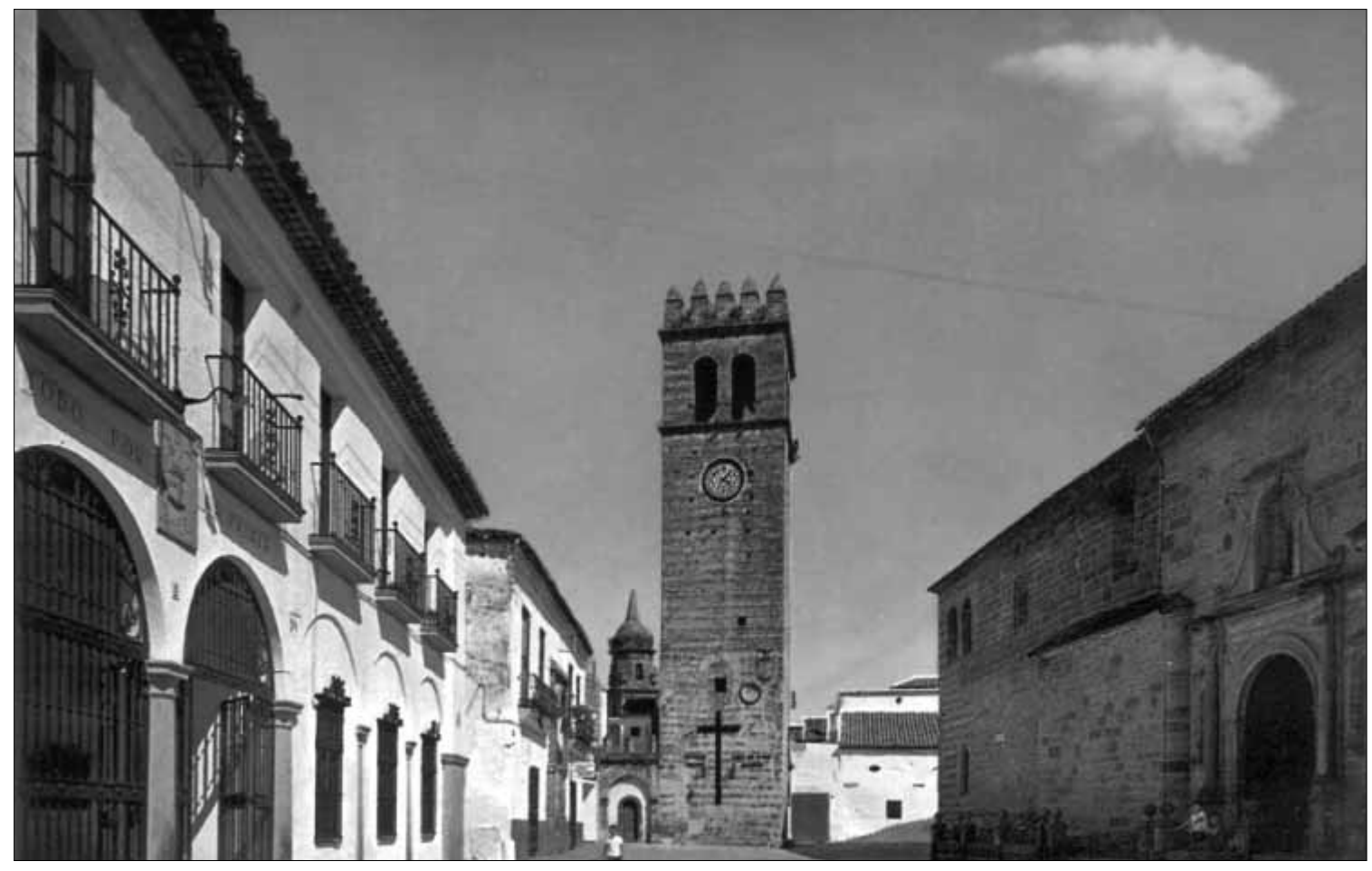

Fig. 3. Torre del Reloj y Plaza de Santa

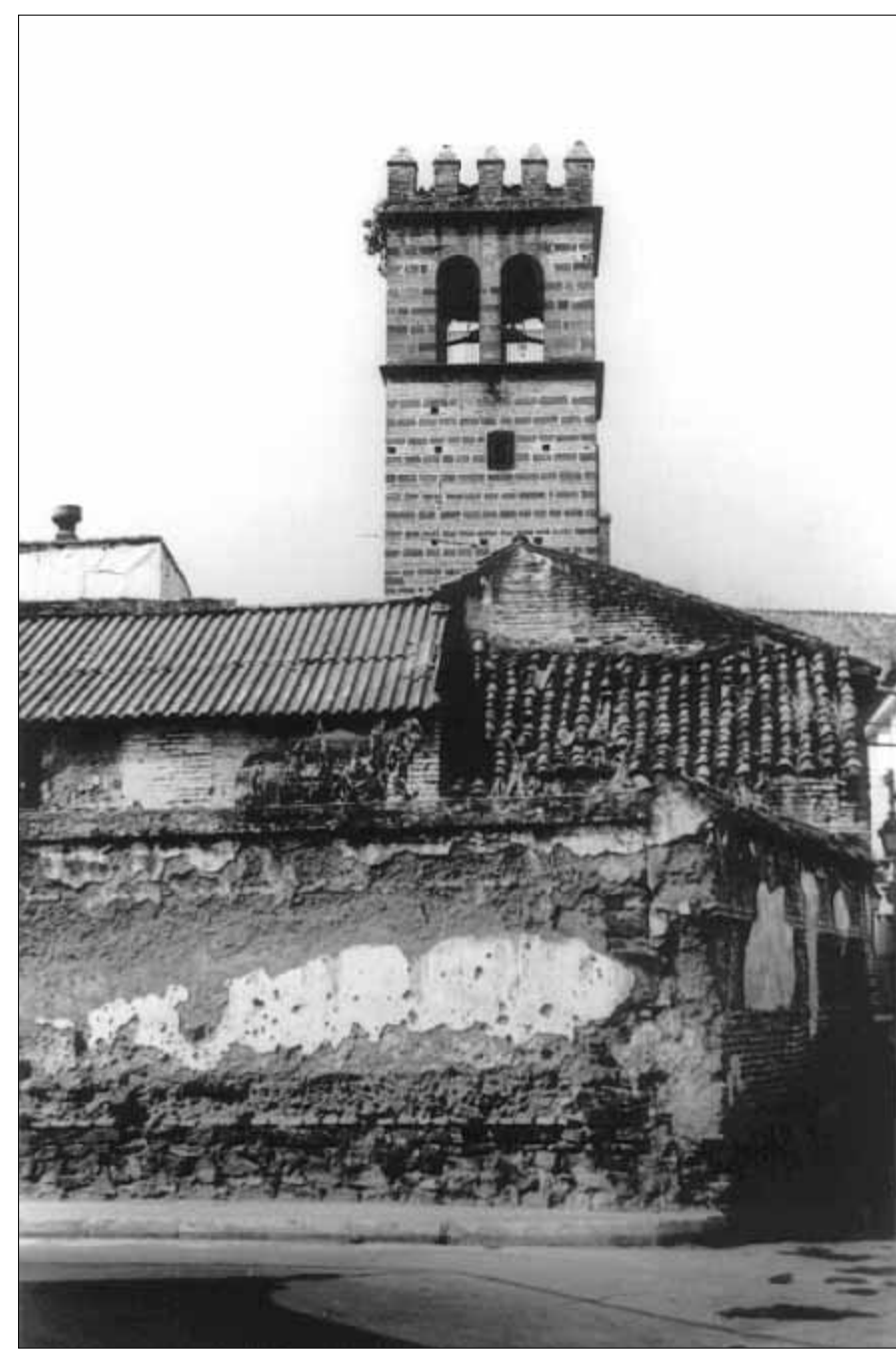

María. Al fondo, San Miguel.

Fig. 4. Torre del Reloj desde el altozano del Carmen. 


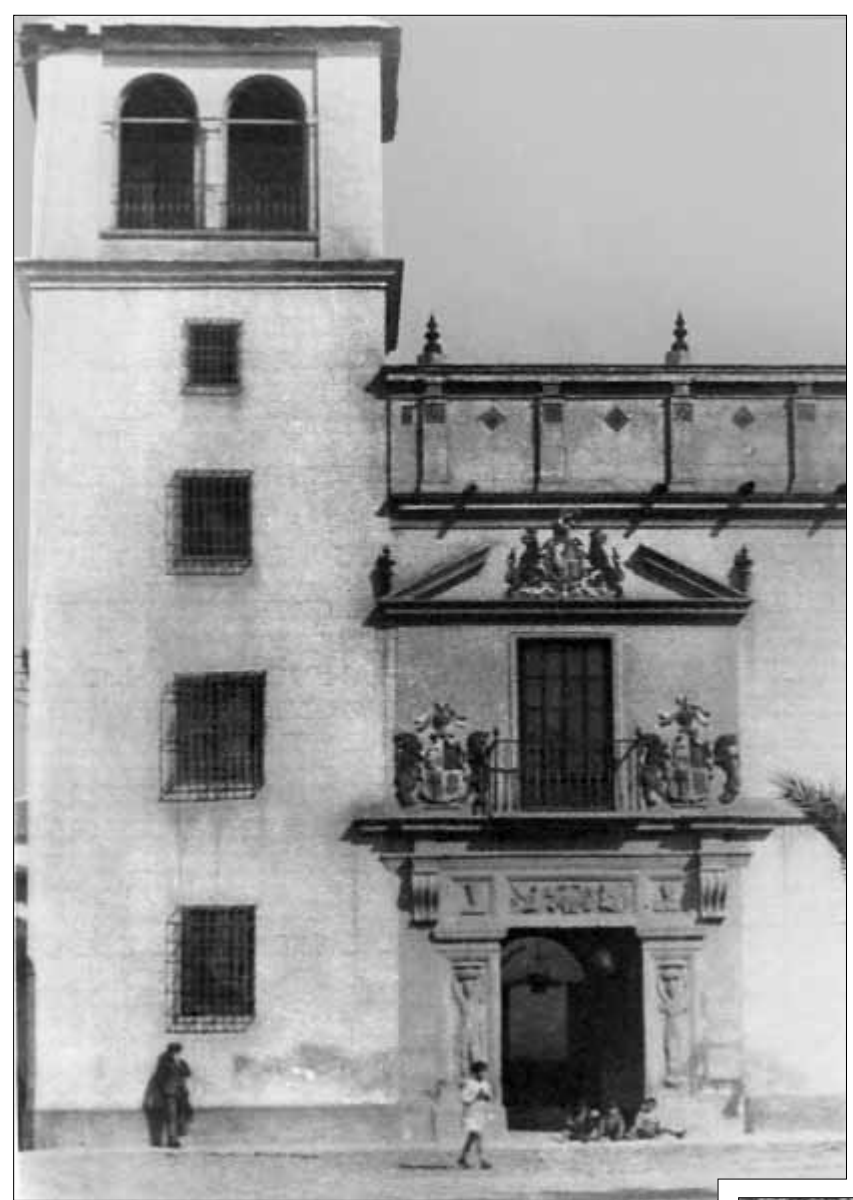

Fig. 5. Casa de la Marquesa de Gracia Real.

Fig. 5. Casa de la Marquesa de Gracia Real. 


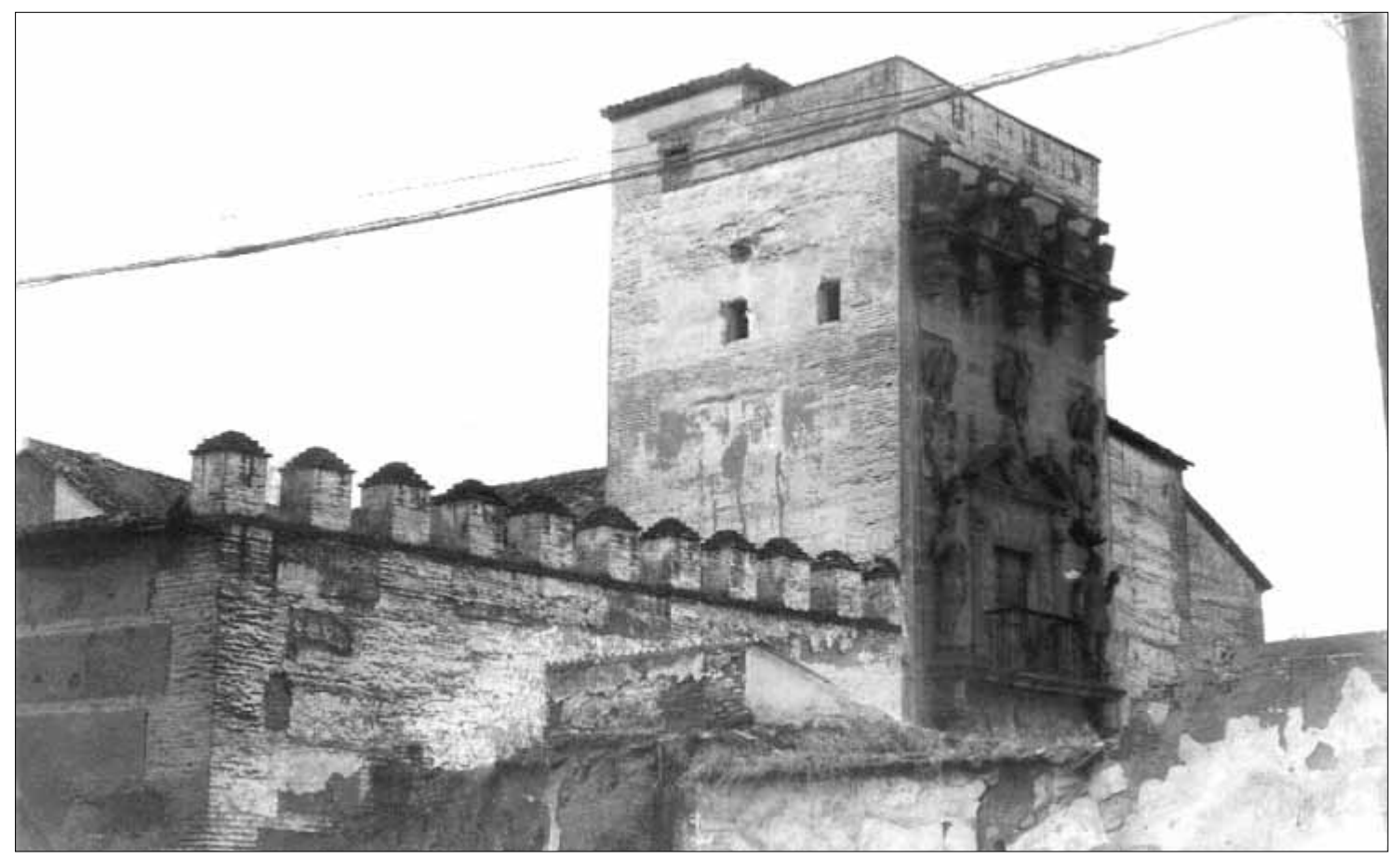

Fig. 7. Fachada torre de la casa Niños de Don Gome.

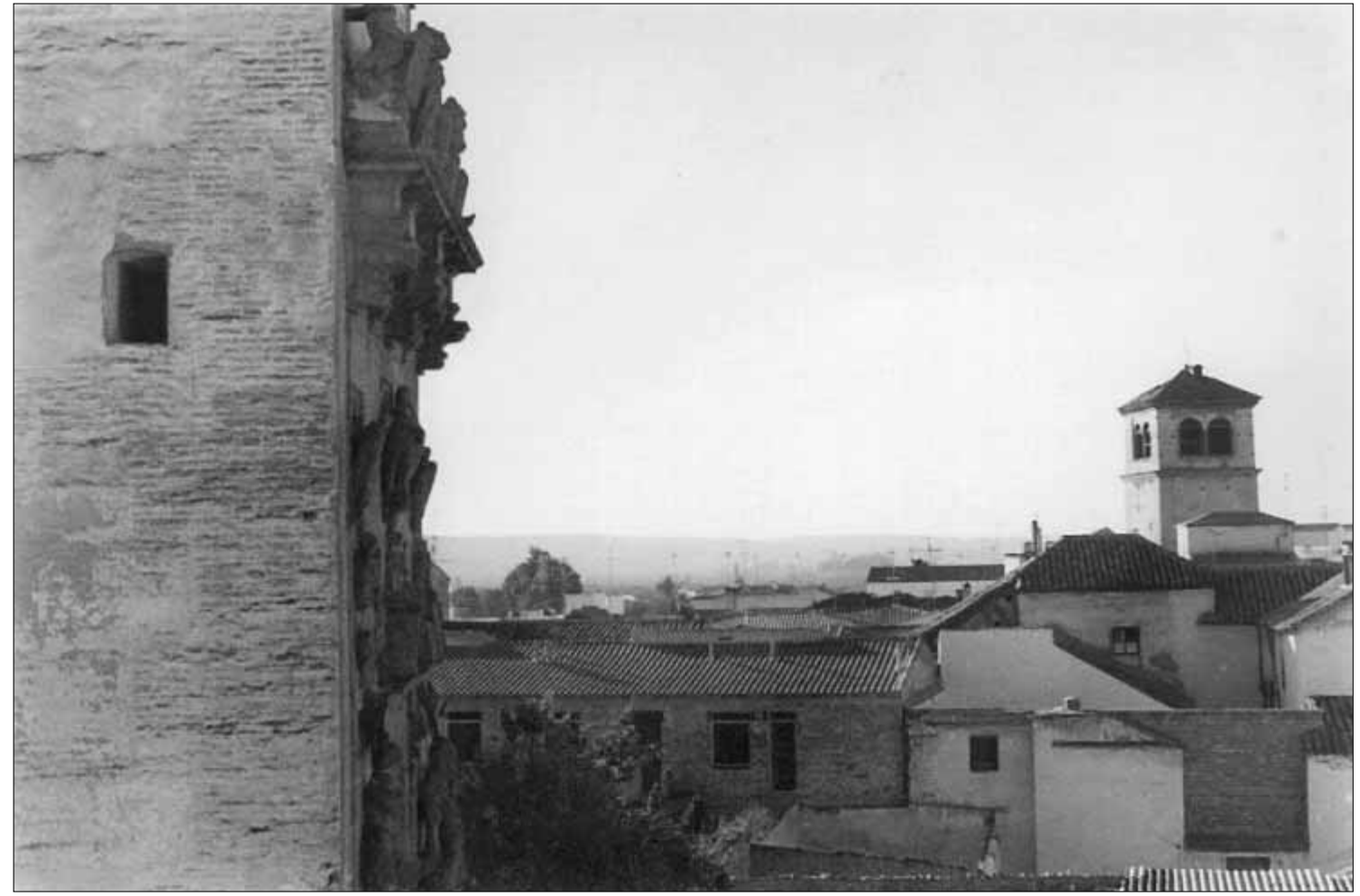

Fig. 8. Casa Niños de Don Gome y al fondo Casa de la Torre. 


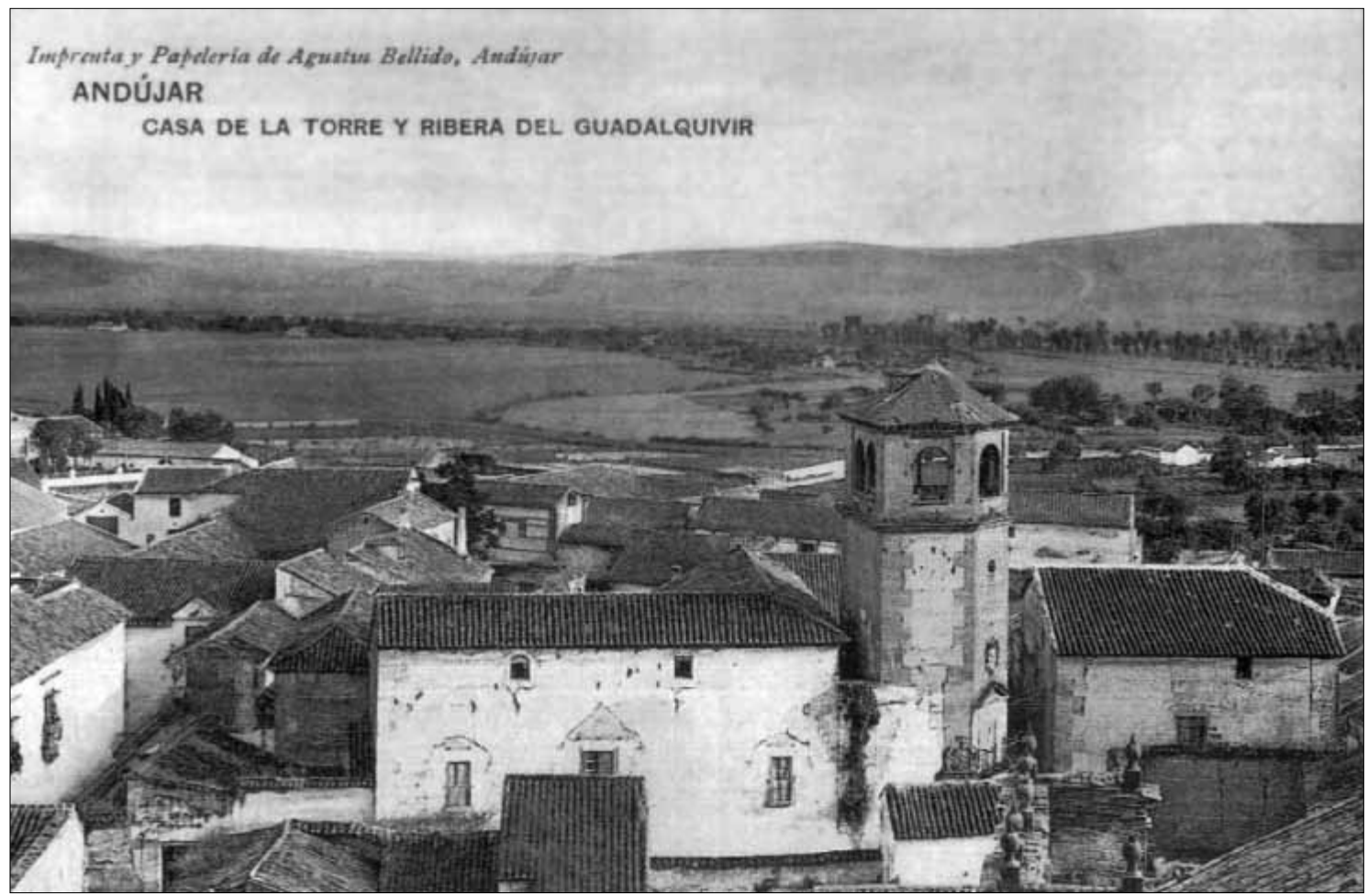

Fig. 9. Casa de la Torre vista desde

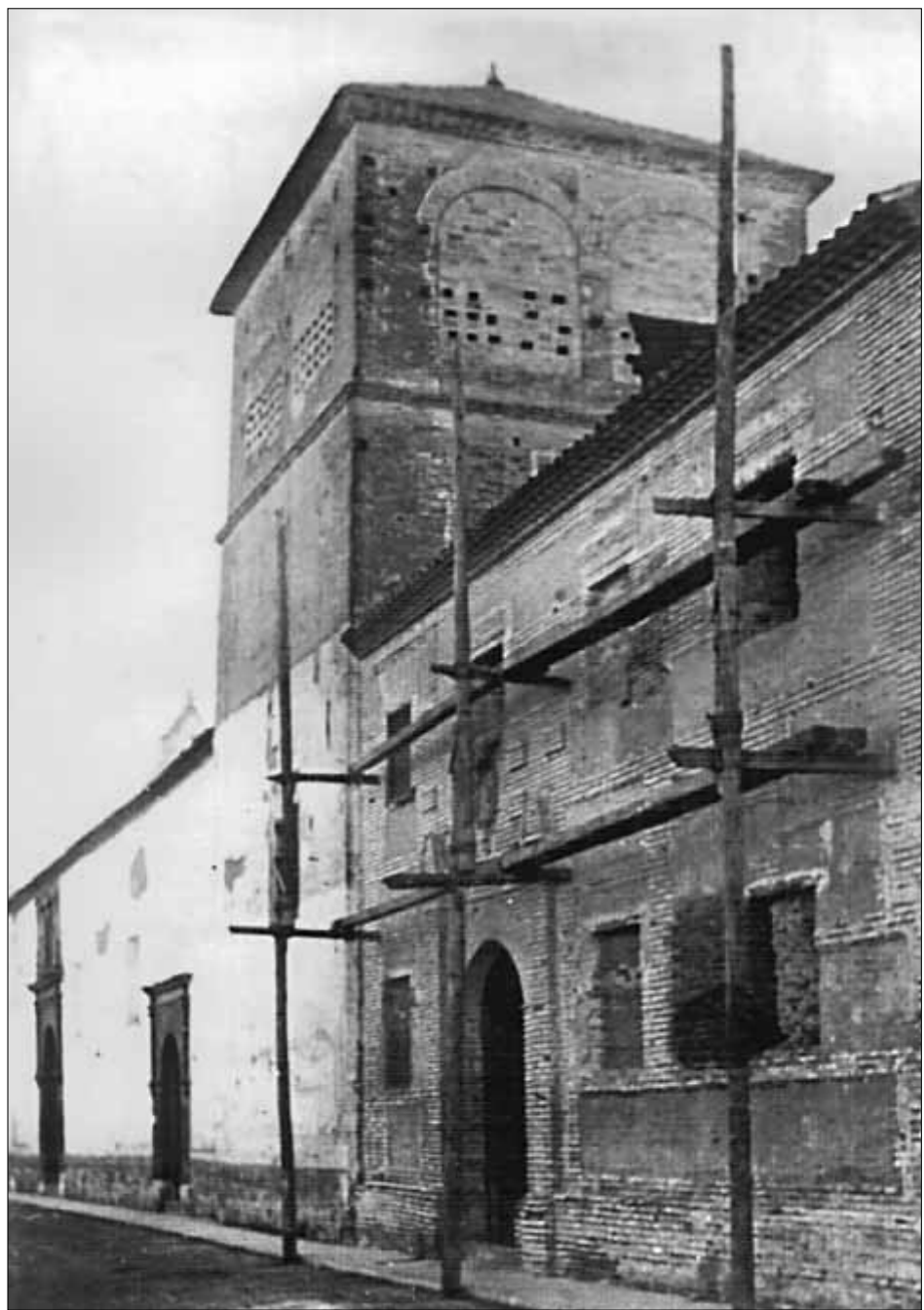
el campanario de San Miguel.

Fig. 10. Torre mirador del Convento de Jesús María. 

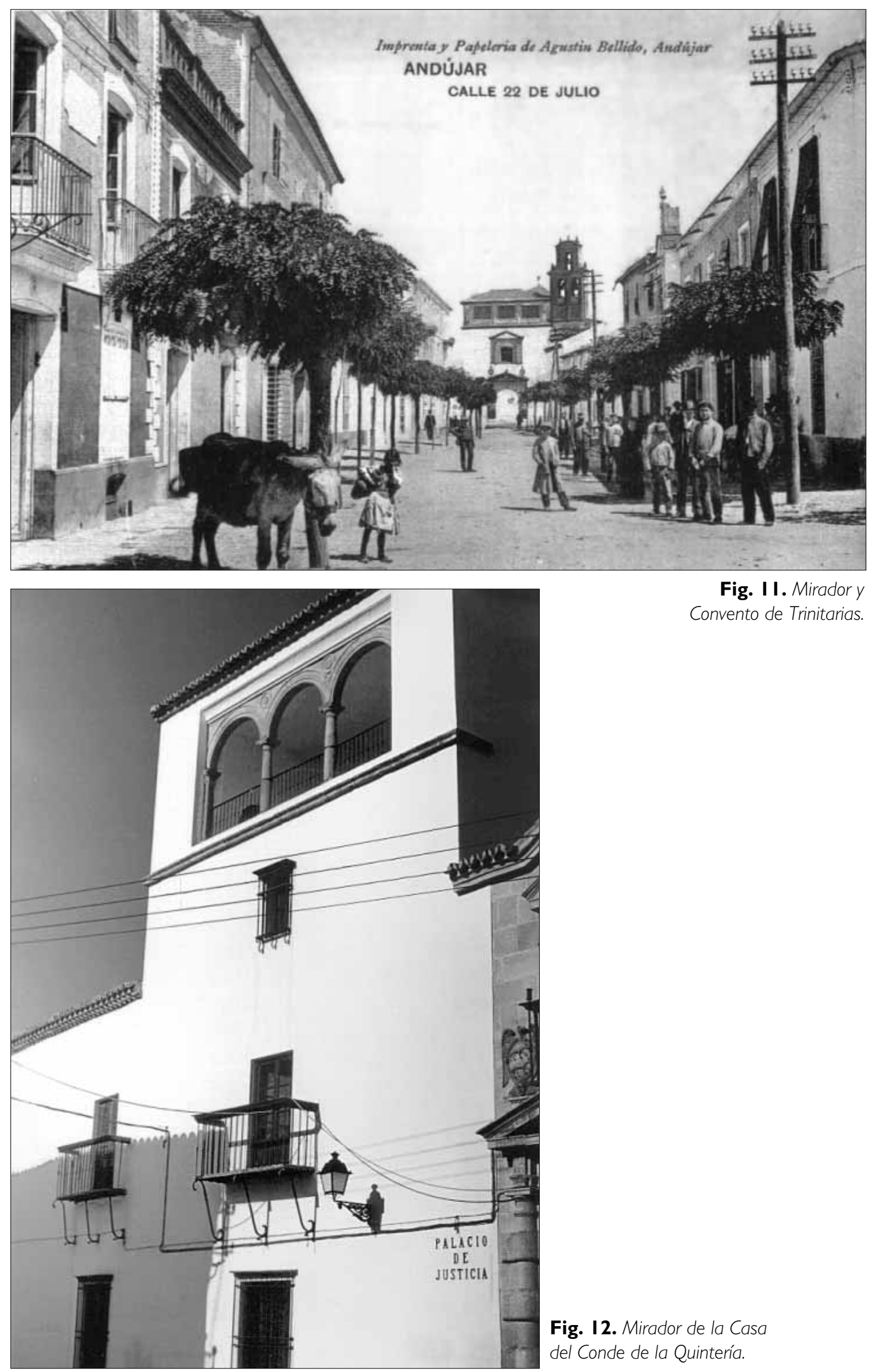

Fig. I I. Miradory Convento de Trinitarias.

Fig. 12. Mirador de la Casa

del Conde de la Quintería. 


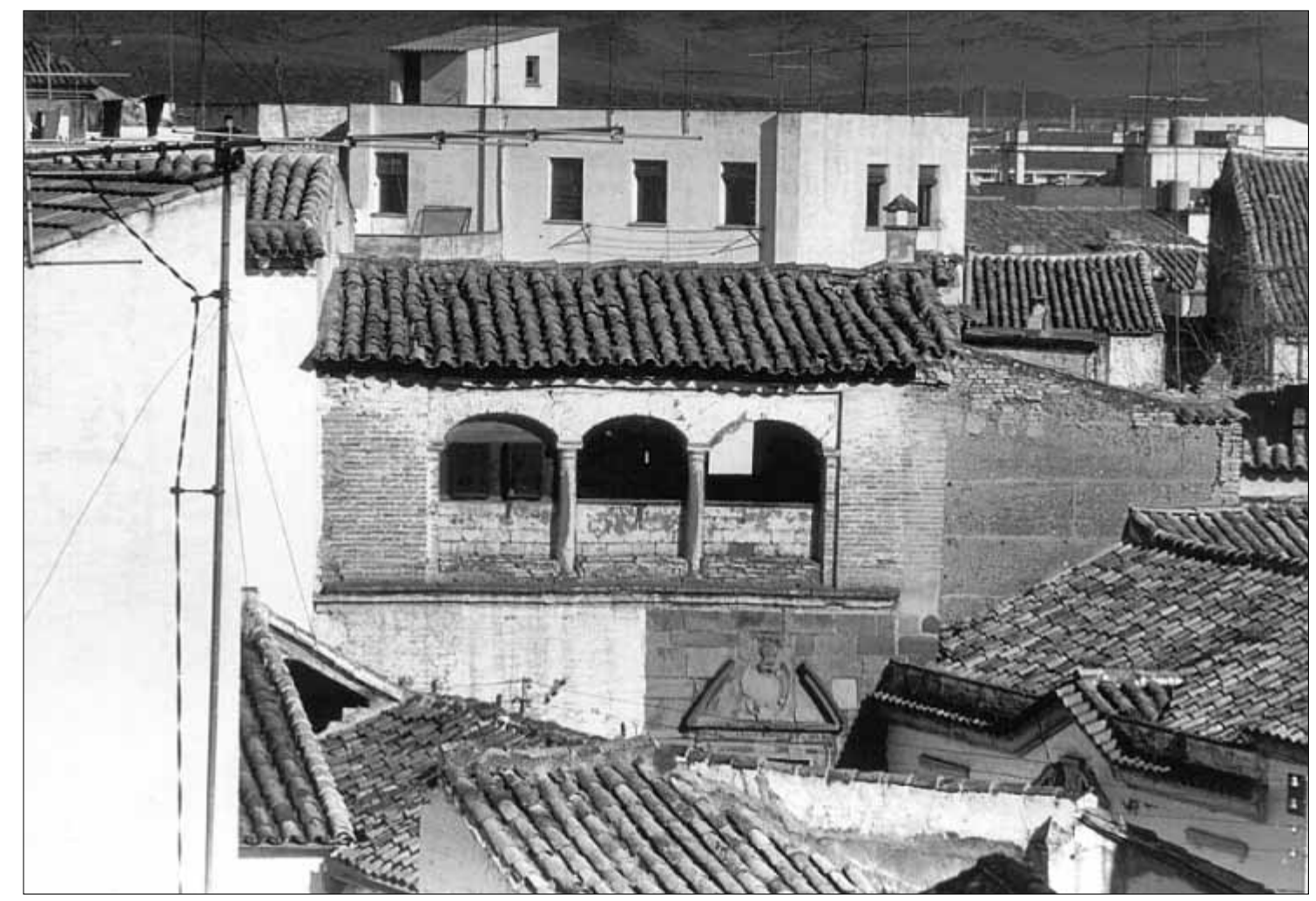

Fig. 13. Mirador de la calle Juan Robledo.

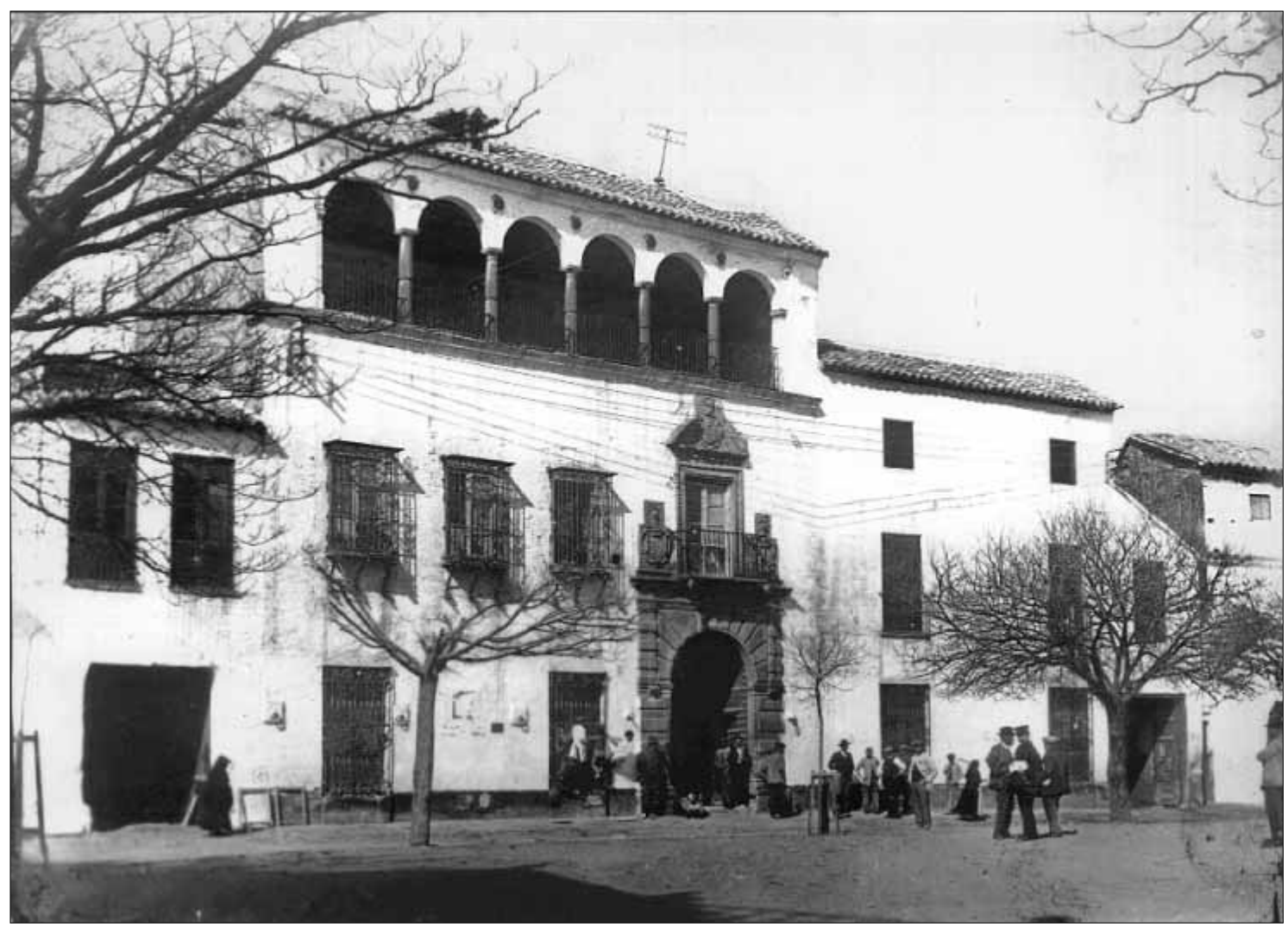

Fig. 14. Mirador de la casa del Marqués del Puente. 


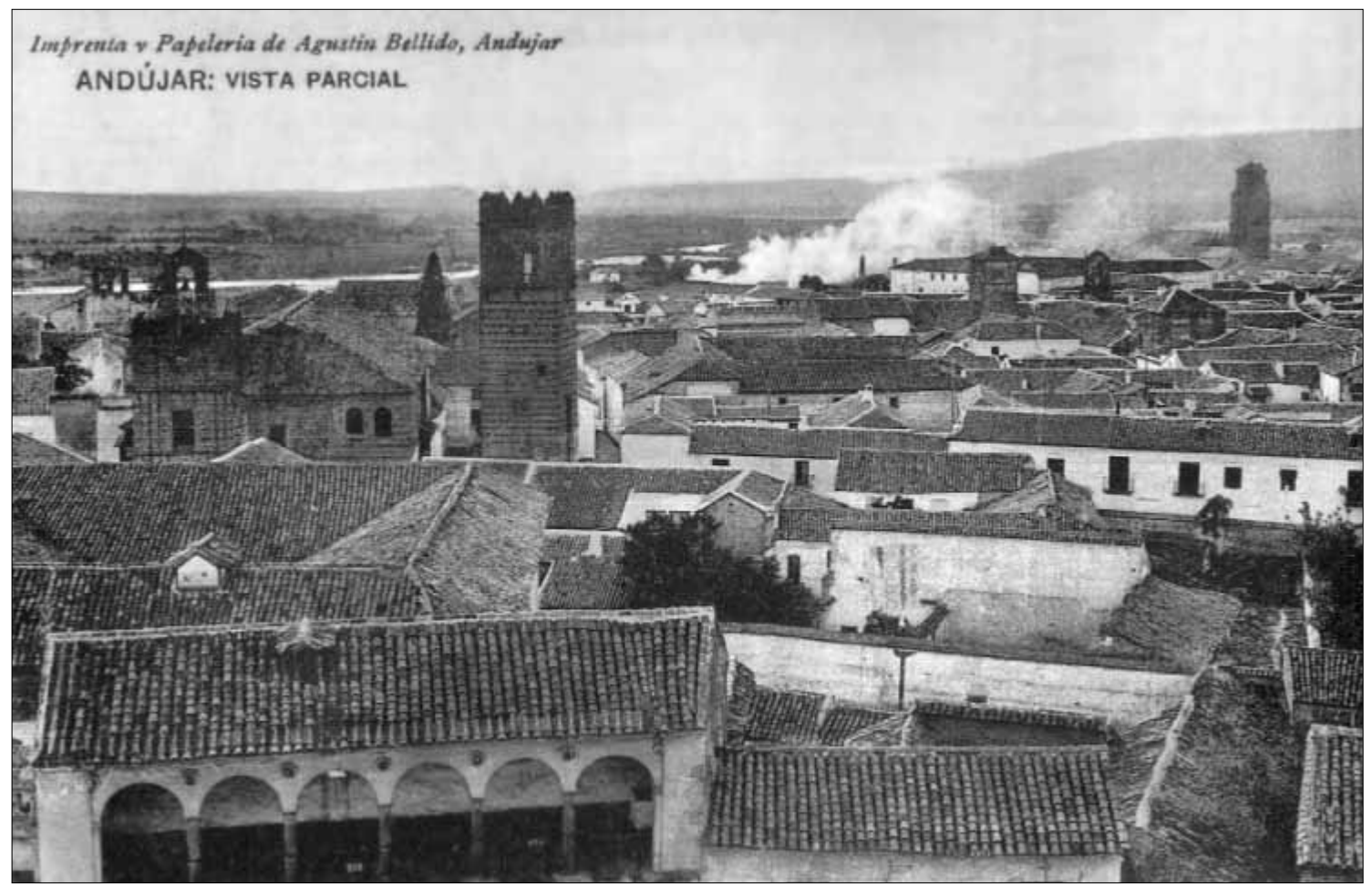

Fig. 15. Miradores del Mercado. Torre del reloj y de Santa María, detrás; a la izquierda, espadaña de Santiago; a la derecha, torre de casa solariega y espadaña de Santa Marina; al fondo, campanario de San Bartolomé. Todo visto desde la Torre de San Miguel.

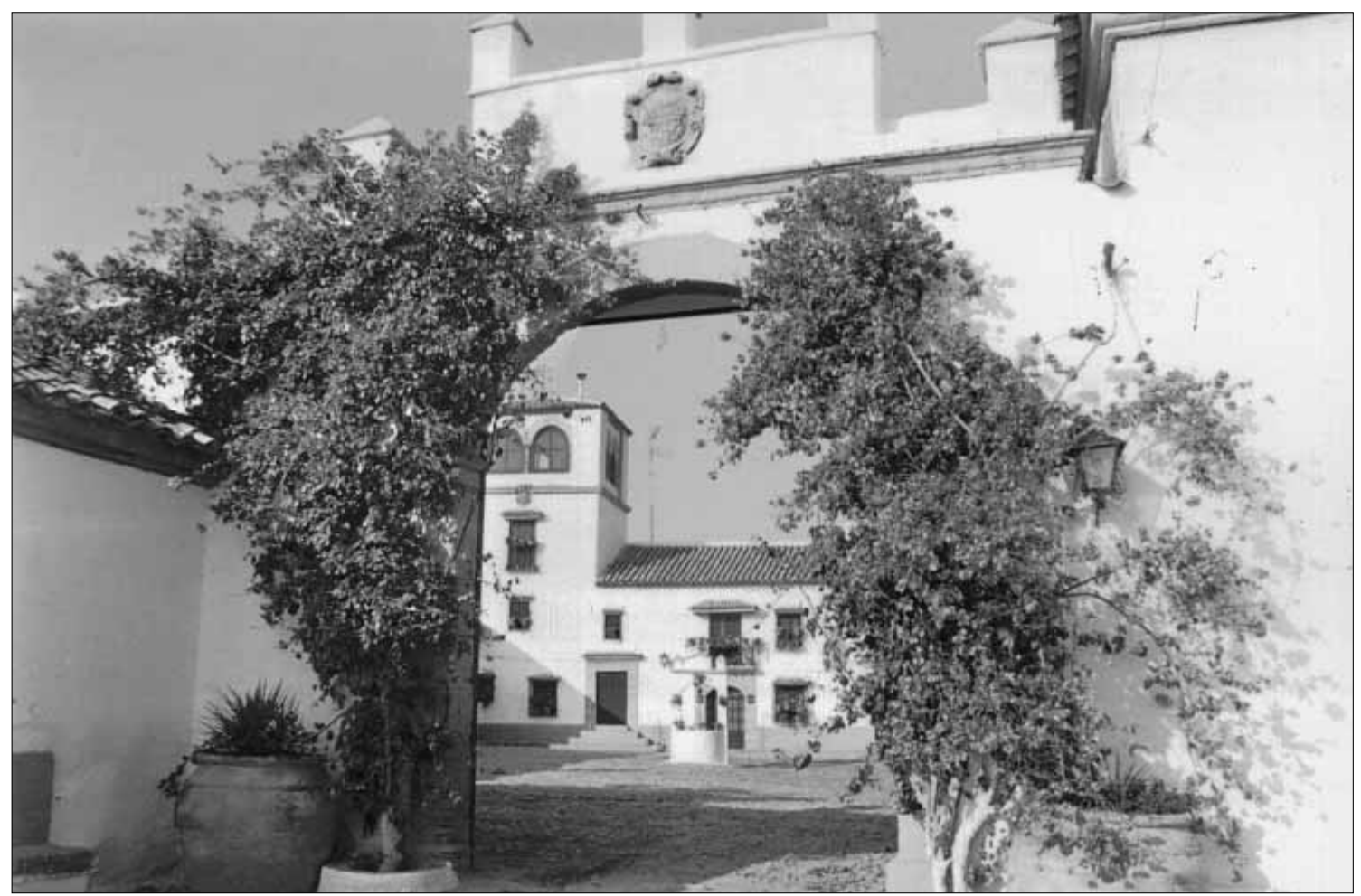

Fig. 16. Casería de la Aldehuela. 


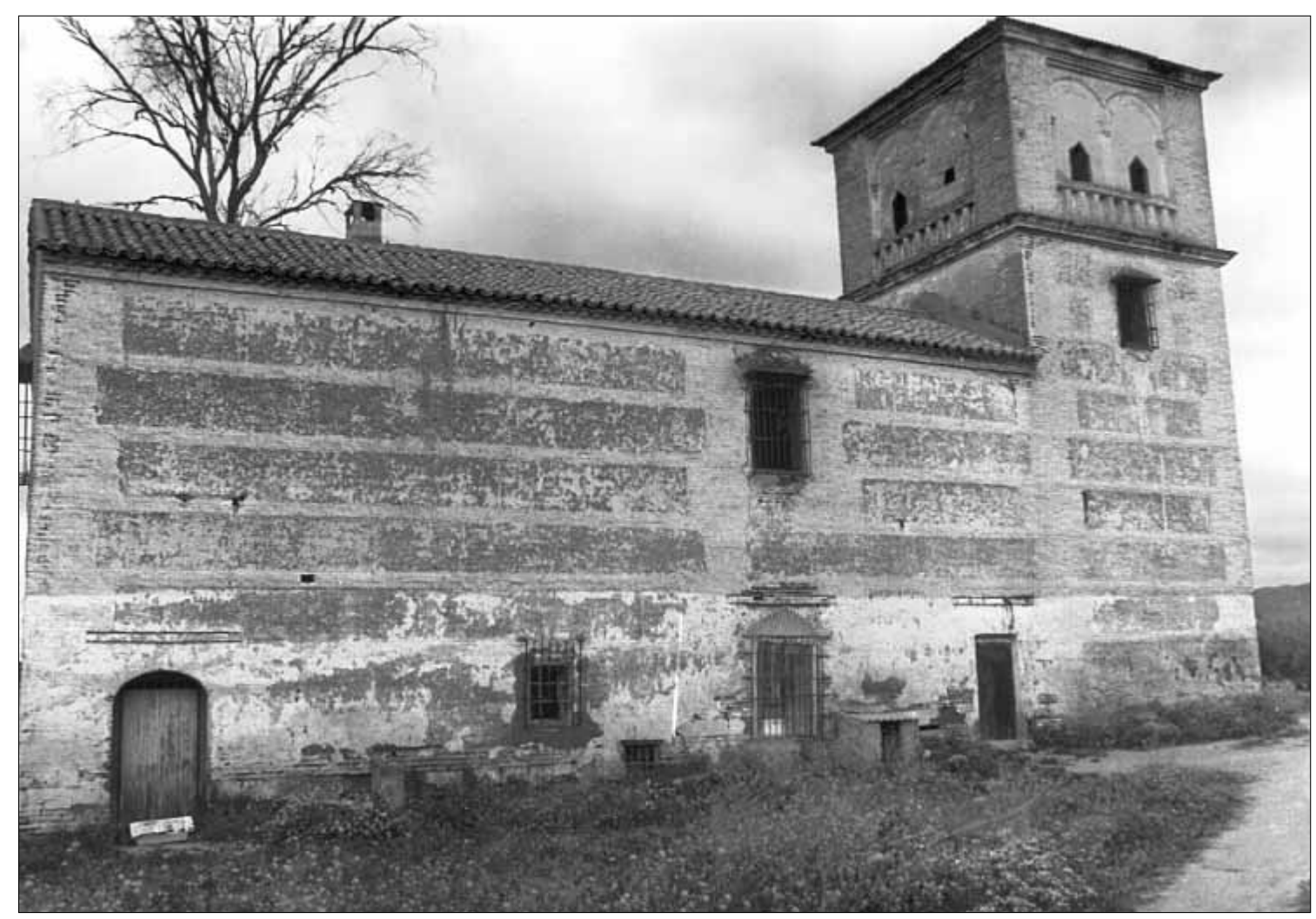

Fig. 17. Casería de la Torre.

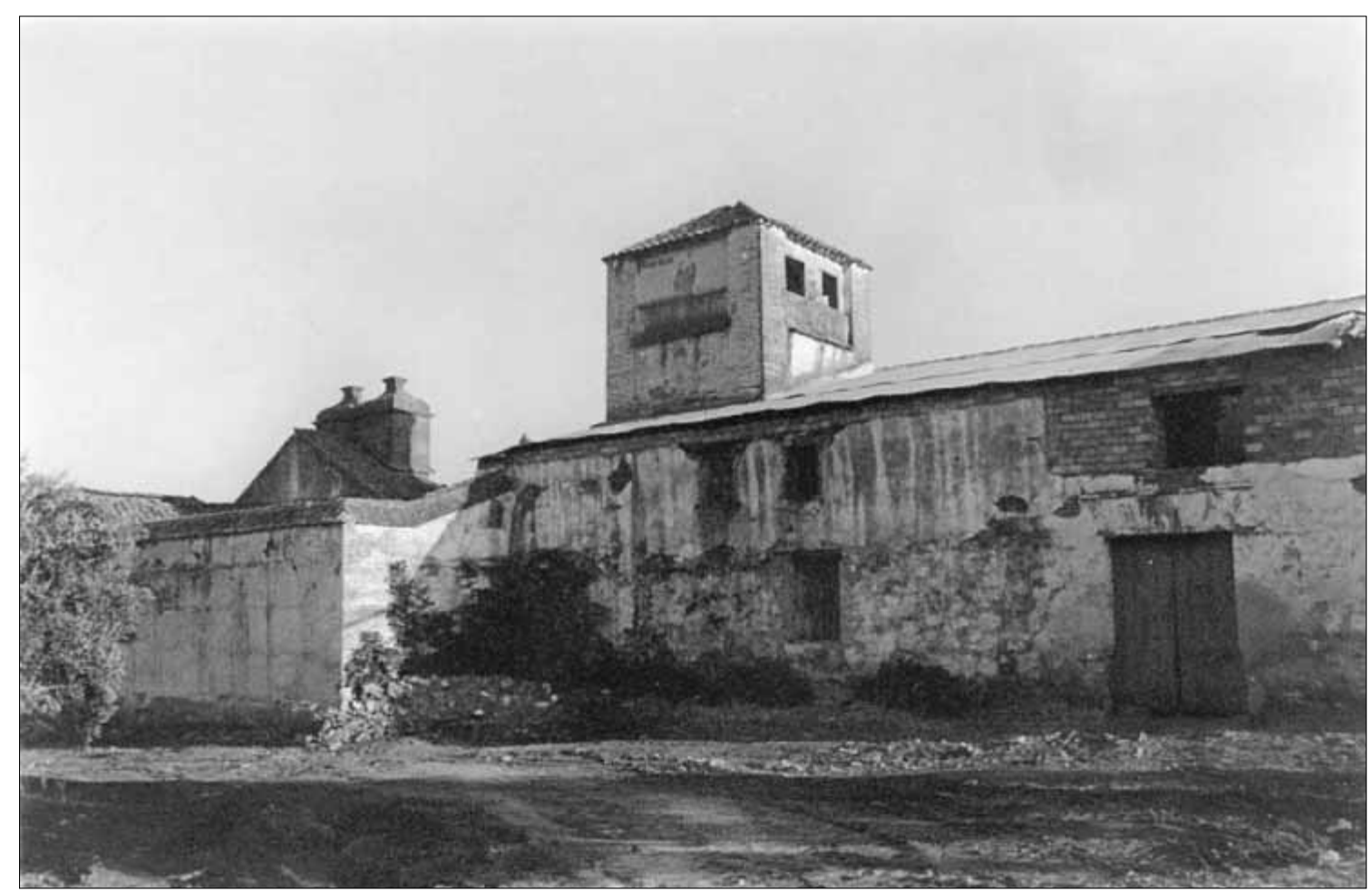

Fig. 18. Cortijo con molino aceitero y torre, en el Km. 314 de la Autovía de Andalucía. 


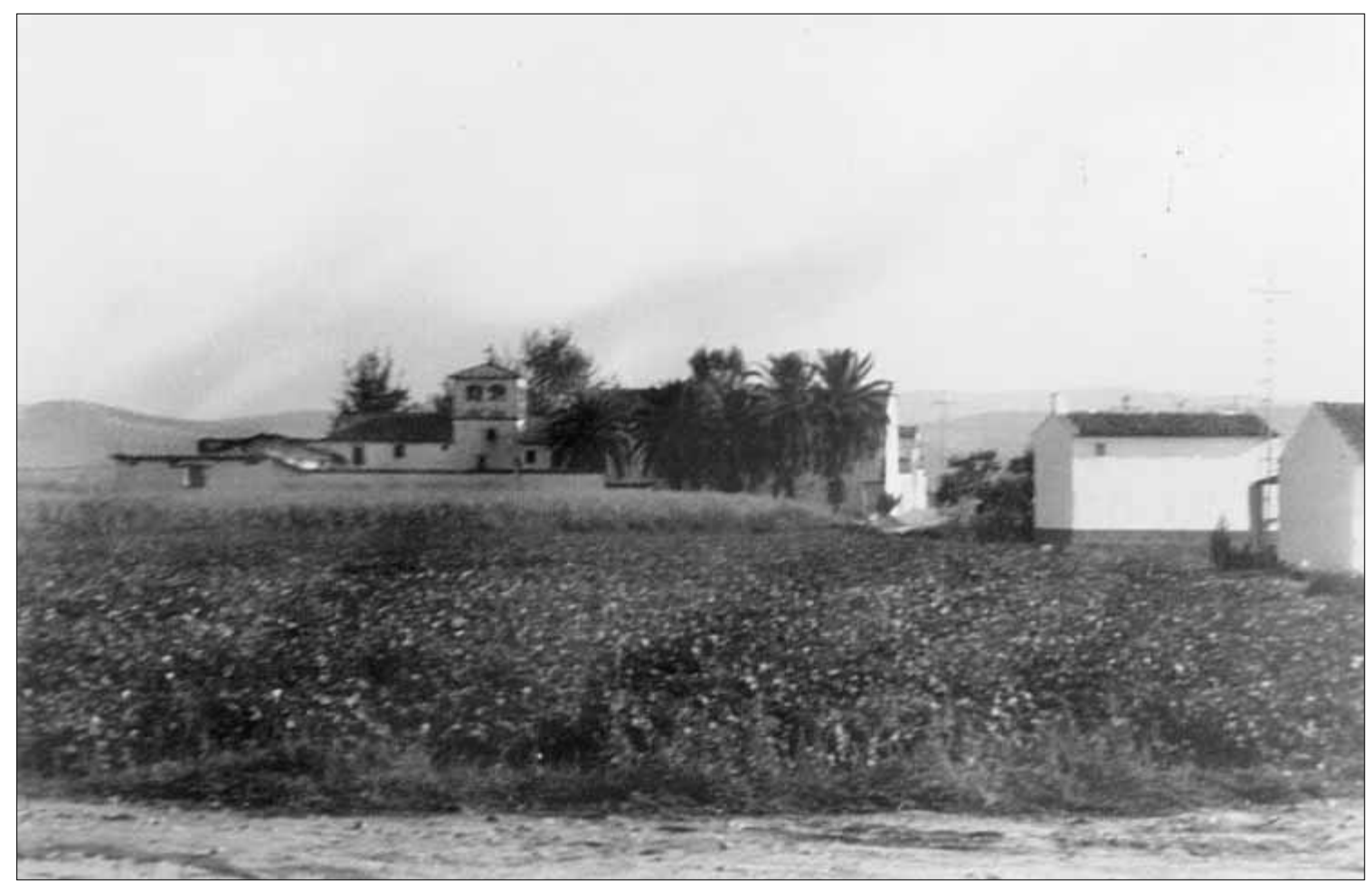

Fig. 19. Casería en

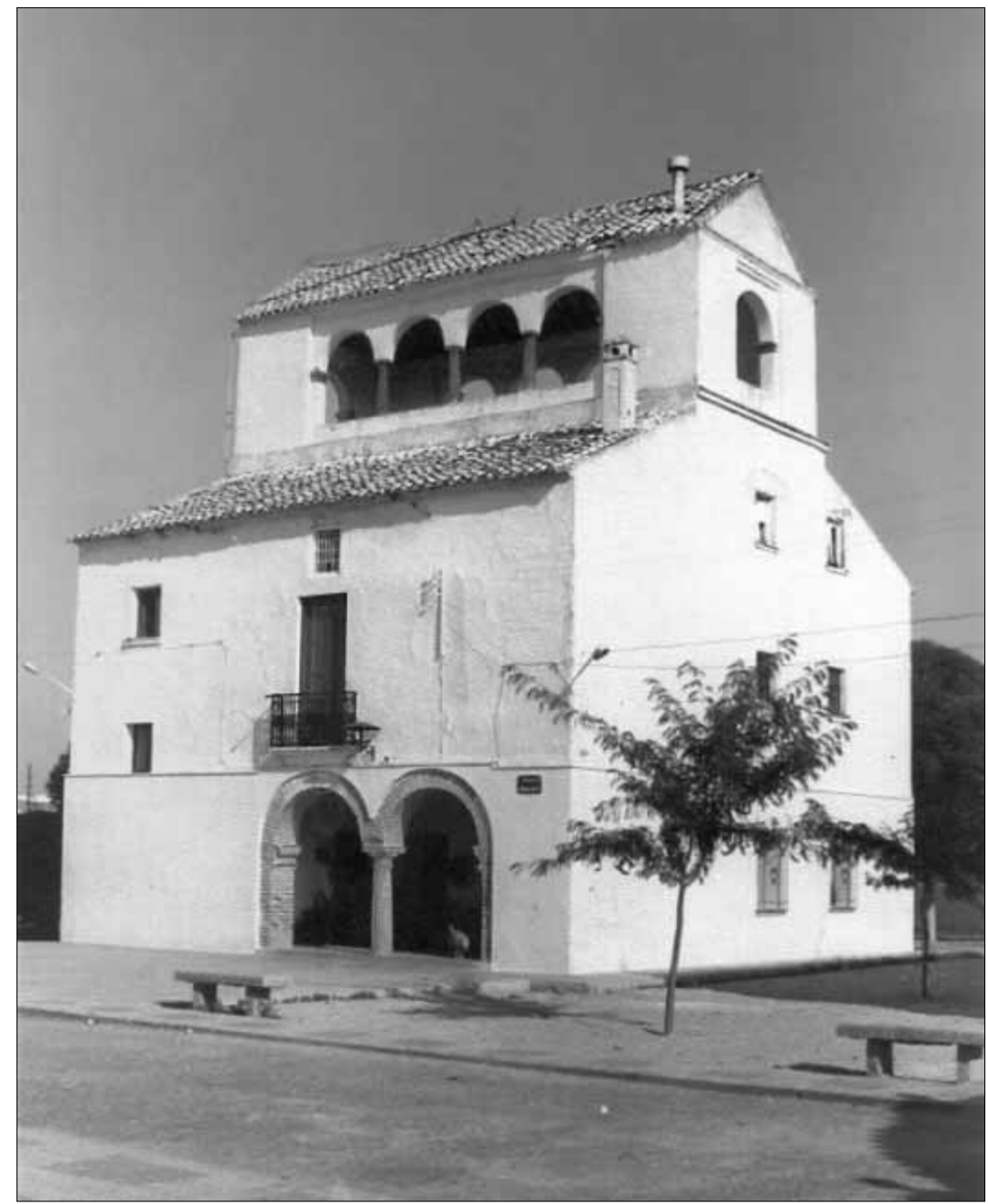

San José de Escobar.

Fig. 20. Casería

de la Quintería. 